\title{
PRAKTIKALITAS PENGEMBANGAN PERANGKAT PEMBELAJARAN DENGAN PENERAPAN MODEL DISCOVERY LEARNING UNTUK MENINGKATKAN KEMAMPUAN BERPIKIR KREATIF
}

\author{
Marintan Butar-butar ${ }^{1}$, Atma Murni' ${ }^{2}$ Yenita Roza ${ }^{3}$ \\ ${ }^{1,2,3}$ Program Pasca Sarjana Pendidikan Matematika, Universitas Riau, Jl. H. R Soebrantas, Riau \\ marintan.butar6261@grad.unri.ac.id
}

\begin{abstract}
Creative thinking ability is consistently approved as a crucial competency for students to optimally and productively learn in this modern education. In fact, observation done by the researcher showed that students' creative thinking abilities were still low in some schools. The ultimate aim of this research is to create learning tools to develop tenth grade students' creative thinking by implementing valid and practical discovery learning on Linear Equation System of Three Variables material. Developing research using R\&D model by Borg and Gall (Musmahmud, 2017) is implemented in this research. Data were collected by administering questionnaires to the students and conducting teachers' observation. The limited trial result indicates that practicality of learning tools is $96.22 \%$ and teacher observation sheet is $91.66 \%$. The findings of this study suggest that creating learning tools by implementing practical discovery learning can develop students' creative thinking abilities.
\end{abstract}

Keywords: Learning Tools, Discovery Learning Model, Mathematical Creative Thinking Ability

\begin{abstract}
Abstrak
Dalam dunia pendidikan, kemampuan berpikir kreatif peserta didik sangat dibutuhkan. Hal ini didasarkan pada informasi yang ditemukan peneliti saat obeservasi di beberapa sekolah bahwa kemampuan berpikir kreatif peserta didik masih rendah. Tujuan riset ini dilakukan yaitu untuk menghasilkan perangkat pembelajaran yang dapat meningkatkan kemampuan berpikir kreatif peserta didik dengan menerapkan model discovery learning yang valid dan praktis untuk materi Sistem Persamaan Linear Tiga Variabel (SPLTV) kelas X SMA. Jenis riset yang dilaksanakan peneliti merupakan penelitian pengembangan yang menerapkan model R\&D oleh Borg and Gall (Musmahmud, 2017). Instrumen pengumpulan data praktikalitas pada riset ini berupa angket respon peserta didik dan lembar pengamatan aktivitas guru. Praktikalitas perangkat pembelajaran pada uji coba terbatas yaitu 96,22\% serta lembar pengamatan aktivitas guru 91,66\%. Kesimpulan pada riset ini yaitu perangkat pembelajaran yang dikembangkan dengan menerapkan model discovery learning praktis untuk meningkatkan kemampuan berpikir kreatif peserta didik.
\end{abstract}

Kata kunci: Perangkat Pembelajaran, Model Discovery Learning, Kemampuan Berpikir Kreatif

\section{PENDAHULUAN}

Dunia pendidikan, secara khusus kurikulum di Indonesia mengalami perkembangan dan perubahan untuk meningkatkan kualitas kemampuan atau kecakapan masyarakat. Kurikulum 2013 adalah kurikulum yang dilaksanakan di Indonesia saat ini. Kurikulum 2013 merupakan upaya pemerintah dalam memperbaiki mutu pendidikan nasional. Kurikulum 2013 telah dirancang oleh pemerintah untuk menolong para guru agar peserta didik dapat memiliki kecakapan atau keterampilan pada masa sekarang (Kemendikbud, 2017).

Kurikulum 2013 sudah mulai menerapkan pembelajaran yang berorientasi pada pendidikan abad 21. Menurut Basuki \& Haryanto (Wardany et al., 2015) karekteristik Skill yang harus dimiliki pada abad 21 yaitu keterampilan yang mampu bersaing dalam masyarakat. 
Menurut Munandar (2009) mengatakan berpikir kreatif merupakan skill berpikir berdasarkan pengetahuan yang dimiliki dari informasi penggalian peserta didik untuk menyelesaikan masalah dengan jabawan yang tepat dan memiliki banyak gagasan atau ide. Kreativitas dapat diartikan sebagai kemampuan berpikir seseorang dalam memberi ide-ide dengan lancar, memberi banyak jawaban dengan tepat atau lentur, orisinil serta dapat mengolaborasi ide-ide. Menurut Career Center Maine Departmen of Labor USA, kemampuan berpikir kreatif juga sangatlah penting karena hal ini adalah hal yang dibutuhkan di dalam dunia pekerjaan (Mahmudi, 2010). Kemampuan berpikir ini sangat dibutuhkan untuk melatih kemampuan berpikir logis, sistematis, kritis, analitis, kreatif, dan memiliki kemampuan untuk berkolaborasi. Menurut peneliti, hal ini sangat diperlukan kemampuan guru untuk meningkatkan kreativitas peserta didik pada proses pembelajaran matematika. Pengembangan dan penelitian pembelajaran matematika dalam berpikir kreatif harus terus dilakukan.

Berdasarkan wawancara guru yang dilakukan oleh peneliti di SMA ditemukan kemampuan berpikir kreatif peserta didik pada saat proses belajar mengajar di kelas masih kurang. Peserta didik cenderung hanya mencatat dari penjelasan guru yang ada di papan tulis tanpa memahami jelas penjelasan materi yang diajar guru dan meringkas seluruh yang ada dibuku cetak sehingga peserta didik kesulitan dalam mengembangkan jawaban dari berbagai soal matematika yang lebih luas. Untuk mengatasi hal tersebut maka dibutuhkan proses belajar mengajar yang bisa menggali kemampuan berpikir kreatif dari peserta didik.

Model discovery learning merupakan sebuah model yang ada dalam kurikulum 2013 yang menuntut peserta didik agar memiliki kemampuan berpikir kreatif. Menurut teori Hosnan menyebutkan model discovery learning akan membuat perserta didik belajar aktif dan dalam kemampuan proses berpikir akan bertahan lebih lama (Hosnan, 2014). Model discovery learning diartikan sebagai proses pembelajaran yang terjadi jika materi pembelajaran tidak ditunjukkan dalam bentuk akhirnya, tetapi peserta didik dapat mengelola sendiri (Imas Kurniasih dan Berlin Sani, 2014). Sejalan dengan Hosnan, Imas Kurniasih dan Sani, penelitian Rudyanto (2016) dan Purwaningrum (2016) menyatakan penerapan model discovery learning bisa meningkatkan kemampuan berpikir kreatif. Penerapan model ini cara untuk memperbaiki proses belajar yang ada di kelas.

Proses pembelajaran yang baik juga perlu adanya perencanaan kegiatan pembelajaran. Rancangan kegiatan pembelajaran tidak lepas dari istilah perangkat pembelajaran. Menurut (AlTabany, 2014) menyatakan proses belajar mengajar di kelas ada di dalam sebuah perangkat pembelajaran. Daryanto dan Dwicahyono (2014) juga mengatakan bahwa perangkat pembelajaran merupakan kegiatan yang harus dirancang oleh guru terlebih dahulu sebelum pelaksanaan belajar mengajar. Menurut Muhammad Harijanto (Aulia et al., 2019) Perangkat pembelajaran yaitu: Silabus, Rencana Pelaksanaan Pembelajaran (RPP), Lembar Kerja Peserta didik (LKPD), buku pelajaran, serta tes hasil belajar. Dari uraian tersebut dapat dimaknai bahwa perangkat pembelajaran tersebut merupakan sekumpulan sarana yang digunakan oleh guru maupun peserta didik untuk menunjang proses pembelajaran. 
Hasil analisis peneliti dari hasil wawancara di beberapa SMA Pekanbaru mengenai perangkat yang dilaksanakan, ditemukan bahwa perangkat guru belum sesuai dengan Permendikbud No. 22 Tahun 2016 (Kemendikbud, 2016). Mereka juga mengalami kesulitan dalam menyusun RPP. LKPD yang digunakan juga berbentuk soal-soal yang berupa soal yang sering digunakan dalam internet dan buku. Hal inilah yang membuat kemampuan siswa dalam berpikir kreatif belum terasah dengan baik.

Berdasarkan beberapa permasalahan yang ditemukan diperlukan perbaikan pengembangan perangkat pembelajaran yang ada. Peneliti termotivasi untuk mengembangkan perangkat pembelajaran matematika yang menerapkan model discovery learning dalam meningkatkan kemampuan berpikir kreatif pada materi SPLTV kelas X SMA.

\section{METODE}

Model pengembangan yang dilaksanakan oleh peneliti yaitu model pengembangan Borg and Gall dengan langkah-langkah pengembangan yang jelas dan terperinci (Diali, 2017), seperti: (1) pendahuluan dan pengumpulan informasi, (2) perencanaan, (3) pengembangan desain, (4) uji coba terbatas, (5) revisi hasil uji coba terbatas, (6) uji coba skala luas, (7) revisi produk skala luas, (8) uji coba produk akhir, (9) revisi produk akhir, serta (10) deseminasi dan implementasi. Praktikalitas ini ditunjukkan dari uji lanjutan tahap uji coba terbatas dan uji coba skala luas. Pada uji coba terbatas diujikan adalah LKPD untuk 8 peserta didik kelas X SMA dan uji skala luas dilaksanakan sebanyak enam kali pertemuan untuk 36 peserta peserta didik kelas X SMA.

Instrumen praktikalitas adalah lembar yang berisi pernyataan mengenai perangkat pembelajaran yang telah dikembangkan. Lembar praktikalitas terdiri dari lembar pengamatan aktivitas guru dalam menerapkan model discovery learning dan angket respon peserta didik. Pada penelitian ini, lembar praktikalitas disebarkan untuk melihat tingkat keterlaksanaan Silabus dan RPP dan keterbacaan LKPD. Analisis uji praktilaitas dilakukan dengan langkah memberi skor jawaban kategori sangat sesuai (4), sesuai (3), tidak sesuai (2) serta sangat tidak sesuai (1), serta rumus persentase sebagai berikut.

\section{Keterangan:}

$$
\begin{array}{lll}
P=\frac{T_{S e}}{T_{s h}} \times 100 \% & P & \text { : Persentase kepraktisan } \\
& T_{s p} & \text { : Total skor empiris dari pengamat } \\
& T_{s h} & \text { : Total skor maksimal yang diharapkan }
\end{array}
$$

Nilai yang diperoleh kemudian diinterpretasikan dengan kategori kepraktisan pada Tabel 1 di bawah ini untuk mengetahui sejauh mana tingkat praktikalitas perangkat yang dikembangkan. 
Praktikalitas Pengembangan Perangkat Pembelajaran dengan Penerapan Model Discovery Learning untuk

\section{Tabel 1.}

Kriteria Penilaian Praktikalitas

\begin{tabular}{|c|c|}
\hline Interval & Tingkat Praktikalitas \\
\hline $85,01 \%-100 \%$ & Sangat baik \\
\hline $70,01 \%-85 \%$ & Baik \\
\hline $50,01 \%-70 \%$ & Cukup \\
\hline $0,1 \%-50 \%$ & Kurang \\
\hline
\end{tabular}

Sumber: Sa'dun Akbar, 2013

\section{HASIL}

Hasil riset ini dilaksanakan pada uji coba terbatas dan uji coba skala luas. Pada tahap uji coba terbatas, yang diujikan adalah LKPD untuk 8 peserta didik. Berikut ditampilkan pada Gambar 1 persentase angket respon.

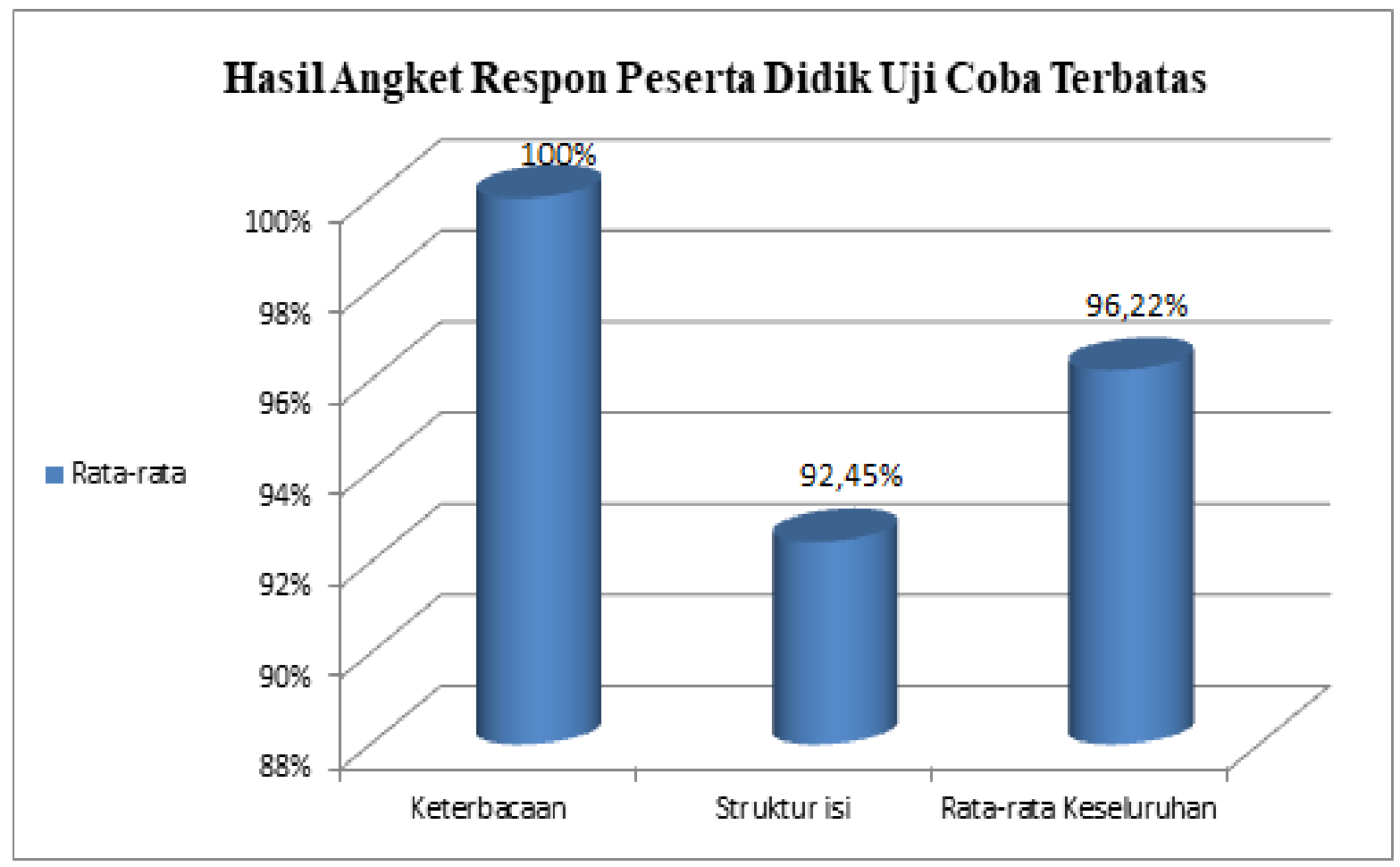

Gambar 1. Hasil Angket Respon

Berdasarkan hasil yang diperoleh nilai rata-rata persentase dari angket respon pada uji coba terbatas mencapai 96,22\% dalam golongan sangat praktis dan saran revisi dari responden untuk perbaikan sebelum dilakukan uji skala luas.

Pada tahap berikutnya akan dilakukan uji kepraktisan untuk Silabus, RPP, dan LKPD. Kepraktisan Silabus dan RPP dilihat dari lembar pengamatan aktivitas guru. Kepraktisan LKPD dilihat dari angket respon peserta didik. Adapun persentase hasil kepraktisan pada LKPD dapat dilihat pada 


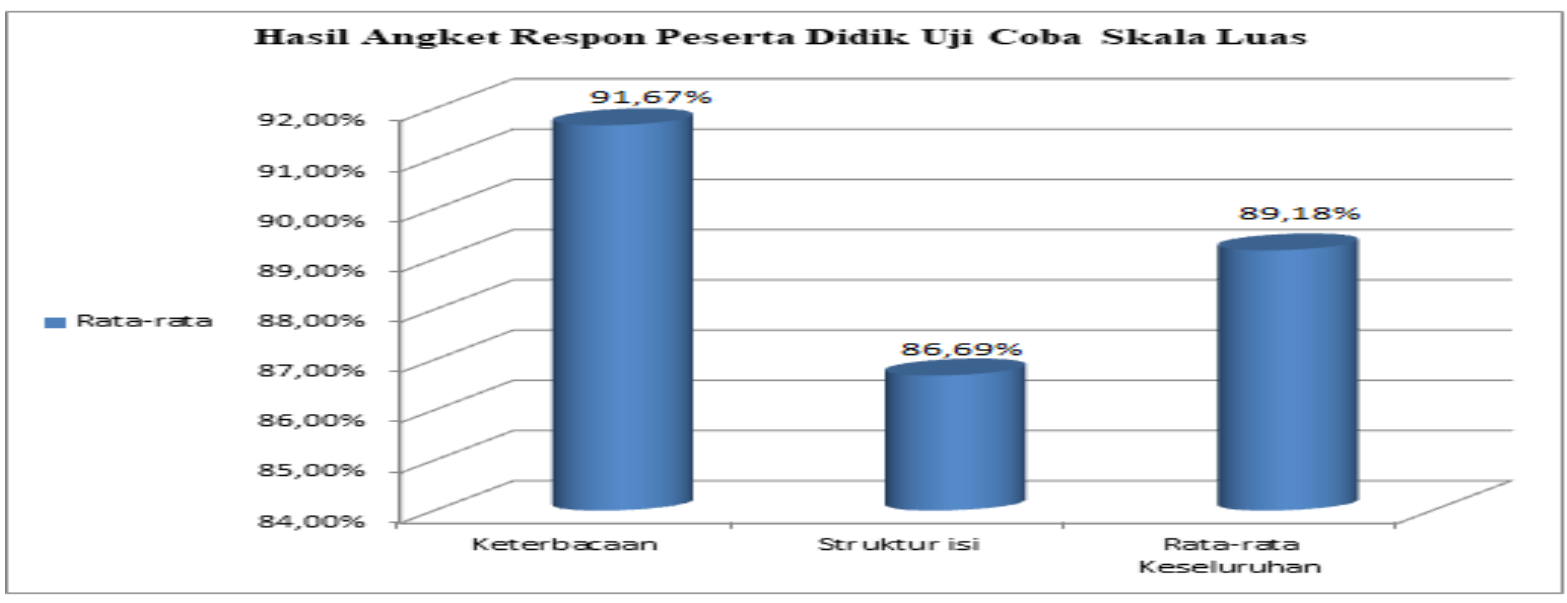

Gambar 2. Hasil Angket Respon

Berdasarkan hasil kepraktisan dari angket respon pada uji coba skala luas diperoleh skor keseluruhan persentase pada 36 peserta didik yaitu 89,18\% dengan kategori sangat praktis. Kategori angket respon ini memperlihatkan bahwa LKPD yang dilaksanakan sudah baik dan hanya terdapat sedikit perbaikan. Selanjutnya akan dilakukan uji kepraktisan untuk Silabus dan RPP. Lembar pengamatan ini merupakan hasil pengamatan aktivitas guru dalam menggunakan silabus dan RPP pada saat proses pembelajaran berlangsung. Hasil lembar pengamatan akan ditampilkan dalam Tabel 2.

\section{Tabel 2.}

Hasil Lembar Pengamatan Aktivitas Guru

\begin{tabular}{|c|c|c|c|}
\hline Aspek Penilaian & Indikator Penilaian & $\begin{array}{l}\text { Rata-rata per- } \\
\text { Indikator }(\%)\end{array}$ & $\begin{array}{l}\text { Rata-rata per- } \\
\text { Aspek }(\%)\end{array}$ \\
\hline \multirow{5}{*}{ Kegiatan Pembuka } & Menyiapkan peserta didik & $100,00 \%$ & \multirow{5}{*}{$97,50 \%$} \\
\hline & Menyampaikan tujuan pembelajaran & $100,00 \%$ & \\
\hline & Menyampaikan motiyasi & $87,50 \%$ & \\
\hline & Menyampaikan apersepsi & $100,00 \%$ & \\
\hline & $\begin{array}{l}\text { Menyajikan informasi dan membentuks } \\
\text { kelompok }\end{array}$ & $100,00 \%$ & \\
\hline \multirow{6}{*}{ Kegiatan Inti } & Stimulation (stimulasi/ pemberianransangan) & $87,50 \%$ & \multirow[b]{6}{*}{$88,41 \%$} \\
\hline & $\begin{array}{l}\text { Problem statement (pemyataan/identifikasi } \\
\text { masalah) }\end{array}$ & $90,63 \%$ & \\
\hline & Data collection (pengumpulan data) & $93,75 \%$ & \\
\hline & Data processing (pengelahan data) & $90,63 \%$ & \\
\hline & Verification (verifikasi) & $81,25 \%$ & \\
\hline & Generalization (generalisasi) & $86,72 \%$ & \\
\hline \multirow{4}{*}{ Kegiatan Penutup } & Memberikan tes informative & $81,25 \%$ & \multirow{4}{*}{$89,06 \%$} \\
\hline & $\begin{array}{l}\text { Melakukankegiatan tindaklanjut dan } \\
\text { pemberian tugas. }\end{array}$ & $81,25 \%$ & \\
\hline & $\begin{array}{l}\text { Menginformasikan rencana kegiatan } \\
\text { pembelajaran }\end{array}$ & $93,75 \%$ & \\
\hline & Menutup pembelajaran & $100,00 \%$ & \\
\hline \multicolumn{3}{|c|}{ Rata-Rata } & $91,66 \%$ \\
\hline
\end{tabular}


Hasil lembar pengamatan aktivitas guru yang ditunjukkan Tabel 2 diperoleh rata-rata keseluruhan kegiatan yang dilakukan pada proses pembelajaran yaitu 91,66\%. Berdasarkan kriteria praktikalitas Silabus dan RPP diperoleh Silabus dan RPP dengan kriteria "sangat praktis". Berdasarkan Tabel 2, rata-rata dari keterlaksanaan lembar pengamatan di atas dalam kategori sangat praktis. Riset ini membuktikan bahwa instrumen pembelajaran matematika yang menerapkan model discovery learning sudah terlaksana dengan baik dan dapat digunakan.

Perangkat pembelajaran pada kelas yang menerapkan model discovery learning untuk meningkatkan kemampuan berpikir kreatif peserta didik sudah memenuhi kriteria praktis. Sependapat dengan teori Hosnan yang menyatakan bahwa model discovery learning akan membuat perserta didik belajar aktif dan dalam proses berpikir akan bertahan lebih lama (Hosnan, 2014). Hasil penelitian Purwaningrum (2016) menyatakan pada waktu menyelesaikan masalah dalam kelompok-kelompok yang berbeda-beda kemampuan berpikir akan diberikan kebebasan untuk menyatakan gagasangagasan. Itulah yang membuat model discovery learning lebih baik daripada pembelajaran konvensional. Menurut Rodiah (2019) juga menyatakan ada kenaikan tingkat belajar peserta didik yang menggunakan model discovery learning untuk materi SPLTV. Perbedaan dengan riset ini yaitu meningkatkan kemampuan berpikir kreatif peserta didik untuk materi SPLTV dengan penerapan model discovery learning. Penelitian Chrysmawati et al. (2017) menunjukkan pembelajaran yang menerapkan model discovery learning ada peningkatan kemampuan berpikir kreatif matematis. Hasil riset didukung menggunakan penerapan kemampuan berpikir kreatif yaitu kemampuan seseorang dalam menghasilkan beragam ide dalam mengerjakan suatu masalah menggunakan gagasan yang berbeda dari yang ada sehingga peserta didik termotivasi untuk mengikuti pembelajaran dan mampu mengerjakan hingga menyelesaikan soal.

Berdasarkan analisa peneliti dari hasil riset dan teori yang ada, pengembangan perangkat pembelajaran ini sangat perlu diterapkan dalam proses pembelajaran untuk memotivasi peserta didik untuk mengikuti proses pembelajaran.

\section{KESIMPULAN}

Kesimpulan dari hasil riset ini adalah perangkat pembelajaran untuk Sistem Persamaan Linear Tiga Variabel dengan menerapkan model discovery learning sangat praktis untuk meningkatkan kemampuan berpikir kreatif matematis. Hasil uji coba terbatas mencapai 96,22\% dalam kategori sangat praktis, sehingga perangkat pembelajaran yang telah dikembangkan bisa dijadikan oleh guru untuk bahan alternatif pada proses pembelajaran. Saran pada penelitian ini yaitu materi yang diujikan dalam produk ini terbatas yaitu untuk materi SPLTV pada kelas X SMA hanya satu sekolah. Oleh sebab itu saran dalam penelitian ini untuk berikutnya yaitu dapat memakai populasi besar agar hasil penelitian yang diharapkan semakin baik. 


\section{DAFTAR PUSTAKA}

Al-Tabany, T. I. B. (2014). Mendesain model pembelajaran inovatif, progresif, dan kontekstual. In Prenadamedia Group.

Aulia, M., Suanto, E., Program, M. E., \& Sciences, N. (2019). The developing of learning instruments based on experiential learning model on subject Of circle for 8th grade students of Junior high school. 6, 1-12.

Chrysmawati, L., Taufik, A., \& Riyadi, M. (2017). Penerapan Model Discovery Learning Berbantuan Alat Peraga Pentas Trigonometri untuk Meningkatkan Kemampuan Berpikir Kreatif Matematis Siswa. Seminar Nasional Pendidikan Matematika 2017, 1(1), 73-84.

Daryanto dan Dwicahyono, A. (2014). Pengembangan Perangkat Pembelajaran. Yogyakarta: Gava Media.

Diali, M. (2017). Tesis Pengembangan perangkat pembelajaran matematika SMP kelas VIII berorientasi HOTS.

Hosnan, M. (2014). Pendekatan Saintifik dan Kontekstual dalam Pembelajaran Abad 21 Kunci Sukses Implementasi Kurikulum 2013. In Bogor: Ghalia Indonesia.

Kemendikbud. (2016). Permendikbud Nomor 22 Tahun 2016 Tentang Standar Proses. Journal of Knowledge Management. https://doi.org/10.1016/j.cya.2015.11.011

Kemendikbud. (2017). Panduan Penilaian oleh Pendidik dan Satuan Pendidikan untuk Sekolah Menengah Pertama.

Mahmudi, A. (2010). Mengukur Kemampuan Berpikir Kreatif Matematis.

Munandar, U. (2009). Pengembangan Kreativitas Anak Berbakat. Jakarta: Rineka Cipta.

Purwaningrum, J. P. (2016). Kreatif Matematis Melalui Discovery Learning. 145-157.

Rodiah. (2019). Penerapan Model Pembelajaran Dsicovery Learning untuk Meningkatkan Hasil Belajar Matematika Siswa Kelas X.IPA. 2 Semester I SMA Negeri I Bengkalis Tahun Pelajaran 2016/2017. Society, 15(2), 87-103.

Rudyanto, H. E. (2016). Model Discovery Learning Dengan Pendekatan Saintifik Bermuatan Karakter Untuk Meningkatkan Kemampuan Berpikir Kreatif. Premiere Educandum : Jurnal Pendidikan Dasar Dan Pembelajaran. https://doi.org/10.25273/pe.v4i01.305

Sani, I. K. dan B. (2014). Sukses Mengimplementasikan Kurikulum 2013.

Wardany, K., Sajidan, \& Ramli, M. (2015). Penyusunan Instrumen Tes Higher Order Thinking Skill Pada Materi Ekosistem SMA Kelas X. Seminar Nasional XII Pendidikan Biologi FKIP UNS. 